\title{
Serum Copeptin Levels in Obstructive Sleep Apnea
}

\section{Ebru Sengul Parlak, MD ${ }^{1 *}$, Habibe Hezer, $M D^{1}$, Emine Arguder, $M D^{1}$, Hatice Kilic, $M D^{1}$, Murat Alisik, $M D^{2}$, Gokhan Yalciner, $M D^{3}$, Mehmet Ali Babademez, $M D^{3}$, Ozcan Erel, $M D^{4}$ and Hatice Canan Hasanoglu, MD ${ }^{1}$}

${ }^{1}$ Department of Chest Diseases, Ankara City Hospital, Turkey

${ }^{2}$ Department of Clinical Biochemistry, Polatli State Hospital, Turkey

${ }^{3}$ Department of Otorhinolaryngology, Head and Neck Surgery, Ankara City Hospital, Turkey

${ }^{4}$ Department of Clinical Biochemistry, Ankara City Hospital, Turkey

*Corresponding author: Ebru Sengul Parlak, MD, Ankara Healtyh Integrated Campus, Ankara City Hospital, Ankara, Turkey

\begin{abstract}
Objectives: To evaluate serum copeptin levels in patients with obstructive sleep apnea (OSA) and healthy controls.

Materials and methods: Fifty-eight newly diagnosed OSA patients and thirty-five healthy individuals were enrolled. OSA patients were divided into mild $(5 \geq \mathrm{AHI}<15)$, moderate $(15 \geq A H I<30)$, and severe $(A H I \geq 30)$ groups. Copeptin levels were evaluated and compared between patients and healthy individuals. For the subgroup analysis, OSA patients were divided into two groups, $\mathrm{AHI}<30$ (mildmoderate) and $\geq 30$ (severe) and copeptin levels were compared between the groups.

Results: Copeptin levels were significantly higher in the OSA group compared to the healthy individuals $(p=0.001)$. In severe OSA patients $(\mathrm{AHI} \geq 30)$, copeptin levels were significantly higher than in the mild-moderate group $(p=$ 0.038 ). The analysis showed that copeptin levels $>4.41$ had a $89 \%$ sensitivity and $71 \%$ specificity for APE (AUC 0.831 , 95\% Cl 0.740-0.922).

Conclusion: Serum copeptin levels were found to be associated with OSA, severe OSA. Copeptin levels may be useful for monitoring and determining high-risk patients OSA patients.
\end{abstract}

\section{Introduction}

Obstructive sleep apnea (OSA) is an important public health concern with numerous consequences at the societal level, including motor vehicle accidents, increased cardiovascular morbidity, metabolic dysfunction, and behavioral and cognitive deficit [1].
OSA is characterized by a decrease in, or complete cessation of, airflow despite ongoing efforts to breathe, and is related to oxygen desaturation and sleep fragmentation [2]. The prevalence of OSA has been estimated at $14 \%$ in men and $5 \%$ in women [3]. Diagnosis of OSA is usually made when a patient has an apnea-hypopnea index $(A H I) \geq 5$, along with excessive daytime sleepiness [4].

Diagnosis of OSA usually requires overnight polysomnography (PSG) [1]. Overnight PSG is a significant undertaking and is relatively inaccessible to patients; waiting times for evaluations leading to diagnosis are commonly 3-6 months in the United States and worldwide [5]. Therefore, researchers have investigated more straightforward and less costly tests of potential diagnostic biomarkers for OSA. Several studies have shown that patients with OSA have elevated levels of proinflammatory cytokines, cellular adhesion molecules, and activated circulating neutrophils $[6,7]$. Interleukin-6 (IL6), tumor necrosis factor-alpha (TNF- $\alpha$ ), and high-sensitivity $\mathrm{C}$-reactive protein are the most frequently evaluated biomarkers in OSA [1].

Copeptin is a novel biomarker that has recently been discussed in terms of its role in OSA. Copeptin is the C-terminal fragment of pre-provasopressin, which includes a 39-amino acid glycopeptide [8,9]. Copeptin is released with vasopressin and can be used instead of the latter agent [10-12]. It is an easily measurable pep- 
tide $[8,13]$ and its levels may reflect hemodynamic and osmoregulatory disturbances [2]. Copeptin has been shown to be an important marker for eventual fatal diseases such as stroke, heart failure, and severe sepsis [14]. It is also a prognostic marker in patients with cardiovascular diseases $[9,11,15]$. There are a few, controversial, studies on the use of copeptin as a biomarker in patients with OSA. The aim of this prospective case-control study was to evaluate the serum copeptin levels in patients with OSA, as well as in healthy individuals.

\section{Materials and Methods}

This cross-sectional study was conducted in the Department of Chest Diseases and Department of Otorhinolaryngology, Head and Neck Surgery between August 2016 and July 2017. Approval was given by the local Ethics Committee and informed consent was obtained from all participants.

\section{Patients}

Fifty-eight newly diagnosed OSA patients and 35 healthy individuals were enrolled in this study. Diagnosis of OSA was made when a patient had an $\mathrm{AHI} \geq 5$ by PSG, as well as excessive daytime sleepiness. OSA patients were divided into mild $(5 \geq \mathrm{AHI}<15)$, moderate $(15 \geq \mathrm{AHI}<30)$, and severe $(\mathrm{AHI} \geq 30)$ groups [16]. The control group were randomly selected from among healthy individuals who attended the chest diseases outpatient polyclinic for routine checks. They were evaluated using the Epworth Sleepiness Scale (ESS). Healthy individuals with an ESS score $<5$ were included in the study. Patients younger than 18 years of age and pregnant women were excluded from the study. Copeptin levels were evaluated and compared between in two groups.

In subgroup analysis, OSA patients were divided into two groups according to AHI levels: < 30 [mild-moderate] or $\geq 30$ [severe]. The copeptin levels were compared between the groups. Additionally, cardiovascular diseases such as hypertension and coronary artery dis- ease were compared between the groups.

\section{Polysomnography}

PSG recordings were performed using Philips Respironics equipment in the same center. Data were recorded by electroencephalography, electrooculography, and chin and bilateral anterior tibialis surface electromyography, to explore thoracic and abdominal movements. Oxygen saturation was measured with pulse oximetry. Oronasal air flow was measured by both oronasal thermal sensors and a nasal pressure cannula. Sleep state scoring and respiratory events were evaluated according to the American Academy of Sleep Medicine manual of sleep and associated events (ver. 2.4). AHI was calculated according to the mean number of apneas and hypopneas per hour of sleep [17].

\section{Laboratory tests}

Blood samples were collected from subjects after a minimum 8-hour fast. The collected samples were centrifuged at 1,600 $\mathrm{g}$ for $15 \mathrm{~min}$ and the serum was separated and stored at $-80^{\circ} \mathrm{C}$ until analysis. The serum copeptin levels were measured using an autoanalyzer (Eastbiopharm Co., Ltd, Hangzhou, China) with a commercial kit using an enzymatic colorimetric method.

\section{Statistical analyses}

IBM SPSS Statistics for Windows software (ver. 20.0; IBM Corp., Armonk, NY, USA) was used for the statistical analyses. Normal distribution of the data was evaluated with the Kolmogorov-Smirnov test. Variables were compared in terms of the mean and standard deviation. Student's $t$-test was used to determine differences between group means for continuous variables. The Mann-Whitney $U$ test was used to assess non-normal data. The $\chi^{2}$ test was used to evaluate categorical variables, and $p<0.05$ indicated significance.

\section{Results}

This study enrolled 58 patients with OSA (mean age,

Table 1: Demographic data and laboratory parameters of the OSA and healthy subjects.

\begin{tabular}{|l|l|l|l|}
\hline Variables & OSA group $(\mathbf{n = 5 8 )}$ & Healthy subjects $(\mathbf{n}=\mathbf{3 5})$ & -value \\
\hline Gender, $\mathrm{n}(\%)$ & & & 0.667 \\
\hline Female & $22(37.9)$ & $15(42.9)$ & $20(57.1)$ \\
\hline Male & $36(62.1)$ & $50.08 \pm 10.99$ & 0.711 \\
\hline Age $(\mathrm{y})$ & $50.94 \pm 10.54$ & $29.80 \pm 2.01$ & 0.12 \\
\hline BMl $\left(\mathrm{kg} / \mathrm{m}^{2}\right)$ & $31.19 \pm 4.98$ & $4.17 \pm 3.57$ & 0.001 \\
\hline Copeptin $(\mathrm{ng} / \mathrm{mL})$ & $8.74 \pm 6.27$ & & 0.138 \\
\hline Smoking status, $\mathrm{n}(\%)$ & & $6(18.8)$ & \\
\hline Smoker & $13(22.4)$ & $24(75)$ & \\
\hline Non-smoker & $33(56.9)$ & $5(6.2)$ & \\
\hline Ex-smoker & $12(20.7)$ & & \\
\hline
\end{tabular}

OSA: Obstructive Sleep Apnea; BMI: Body Mass Index; A p-value $<0.05$ was taken to indicate significance. 
$59.66 \pm 19.29$ years) and 35 healthy individuals (mean age, $54.53 \pm 8.99$ years). No significant difference was found between in two groups in terms of age or gender (both $p>0.05$ ). The demographic data and laboratory findings of the OSA and healthy subjects are summarized in Table 1. Copeptin levels were significantly high-

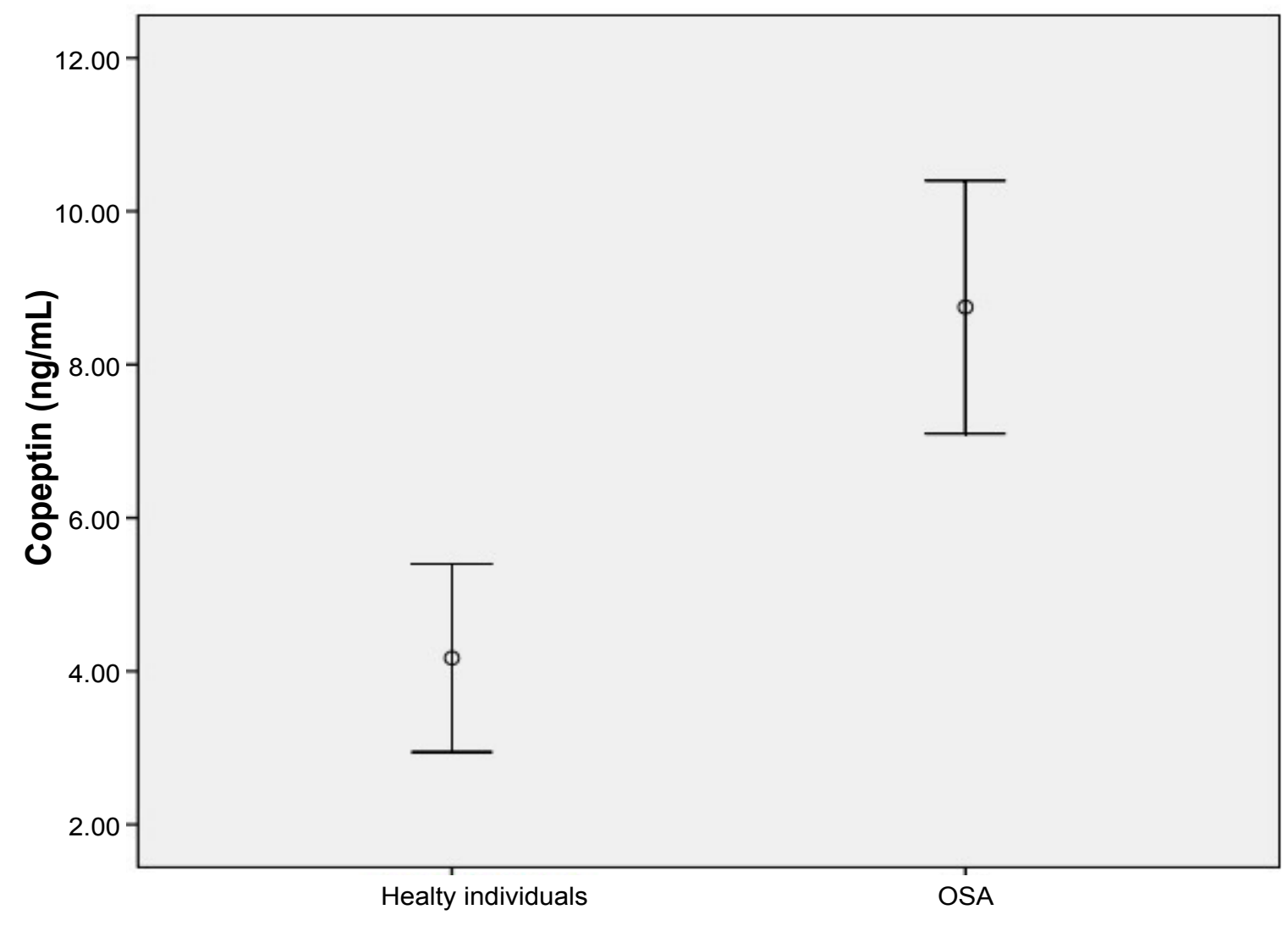

Figure 1: Copeptin levels $(\mathrm{ng} / \mathrm{mL})$ in the two groups $(p=0.001)$.

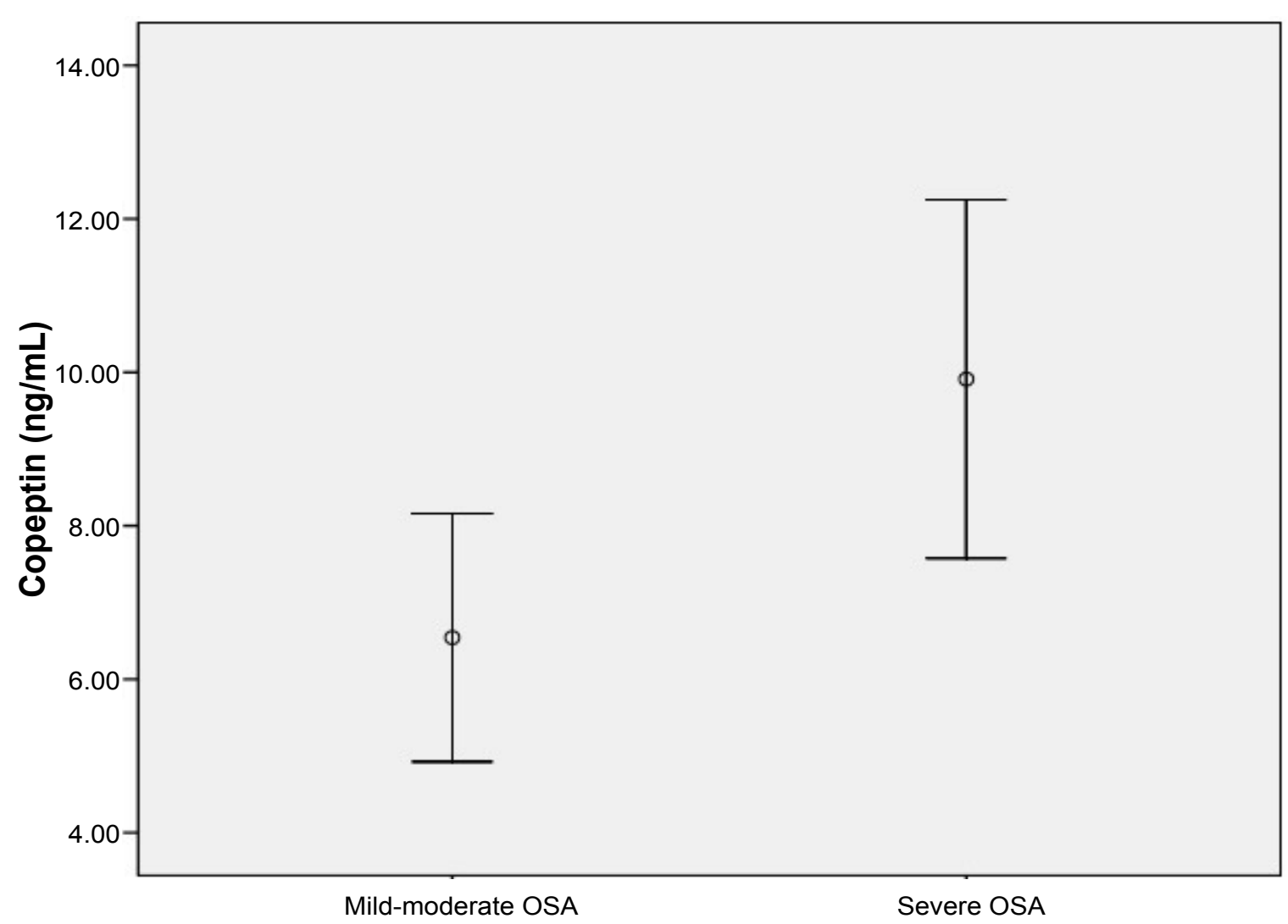

Figure 2: Copeptin levels $(\mathrm{ng} / \mathrm{mL})$ in mild-moderate OSA and severe OSA $(p=0.038)$. 
er in the OSA group compared to the healthy subjects ( $p$ $=0.001$ ) (Figure 1). In 38 patients with severe OSA (AHI $\geq 30$ ), copeptin levels were $9.91 \pm 7.10 \mathrm{ng} / \mathrm{mL}$, while copeptin levels were $6.54 \pm 3.45 \mathrm{ng} / \mathrm{mL}$ in 20 mild-moderate OSA patients $(\mathrm{AHI}<30)$. In patients with severe OSA, copeptin levels were significantly higher than in the mild-moderate group ( $p=0.038$ ) (Figure 2$)$. The analysis showed that copeptin levels $>4.41$ had a $89 \%$ sensitivity and $71 \%$ specificity for APE (AUC 0.831, 95\% $\mathrm{Cl}$ 0.740-0.922) (Figure 3).

Comorbidities with OSA patients shows Table 2. There were not significant differences between the severe OSA and mild-moderate OSA in terms of cardiovascular diseases such as hypertension and coronary artery disease (respectively $p=0.106, p=0.653$ ).

\section{Discussion}

Copeptin levels in this study were found to be significantly higher in the OSA group compared to the healty individuals. Moreover, copeptin levels were significantly higher in patients with severe OSA compared to the mild and moderate groups. Thus, the copeptin levels appears to be associated with OSA severity.

OSA is characterized by recurrent airway obstruc- tion of the posterior pharynx during sleep, leading to hypoxemia and arousals [16]. Intermittent hypoxia is associated with disruption in the normal autonomic and hemodynamic responses to sleep, which are associated with increased sympathetic activity $[4,18,19]$. The repetitive hypoxia and reoxygenation seen in OSA leads to oxidative stress and the generation of reactive oxygen species (ROS), which may play an important role in activating the inflammatory response among patients with OSA [4]. The relationship between OSA and proinflammatory cytokines, such as TNF- $\alpha, \mathrm{IL}-1 \beta$, and IL- 6 , has

Table 2: Comorbidities of the OSA patients.

\begin{tabular}{|l|l|}
\hline Comorbidities, $\mathrm{n}(\%)$ & OSA patients $(\mathrm{n}=58)$ \\
\hline Hypertension & $24(14.1)$ \\
\hline Diabetes mellitus & $14(24.1)$ \\
\hline Coronary artery disease & $6(10.3)$ \\
\hline COPD & $5(8.6)$ \\
\hline Bronchial asthma & $4(6.9)$ \\
\hline Hypothyroidism & $3(5.2)$ \\
\hline Chronic renal failure & $1(1.7)$ \\
\hline
\end{tabular}

OSA: Obstructive Sleep Apnea; COPD: Chronic Obstructive Pulmonary Disease.

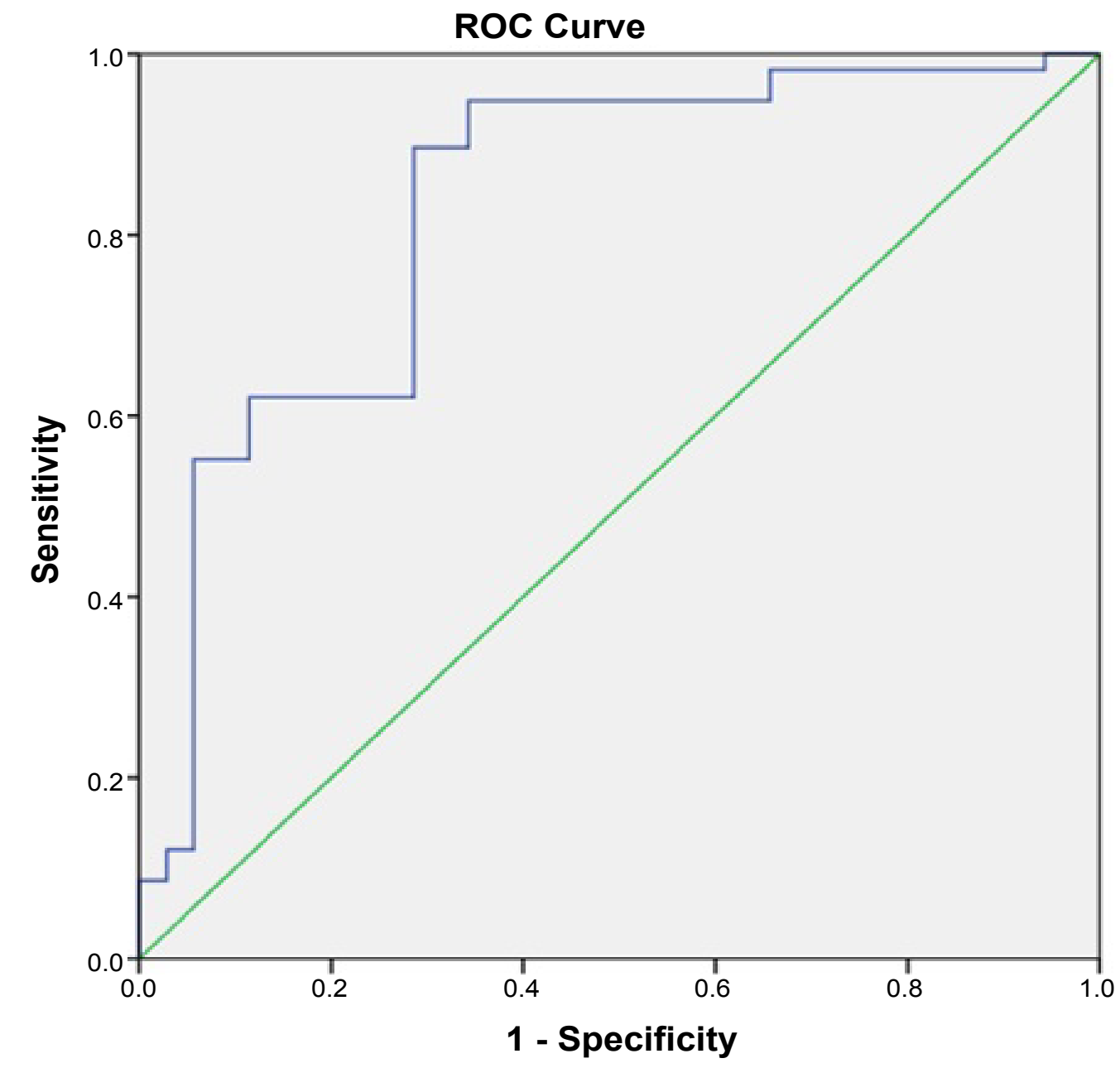

Figure 3: ROC curve for Copeptid associated with obstructive sleep apnea. 
been demonstrated in a number of studies $[20,21]$. It has been shown that decreased levels of adiponectin, a cytokine-like hormone, confers an anti-inflammatory effect in OSA $[16,22,23]$.

Systemic oxidative stress in OSA is an important mechanism linked to cardiovascular disease and metabolic disturbances [24]. In patients with OSA, increased sympathetic activation and inflammatory mediator levels are associated with comorbidities such as hypertension, diabetes mellitus, heart disease, depression, and anxiety disorders [25]. Repeated sleep-related apneas have been associated with cyclic variations of sympathetic muscle activity, and each apneic event leads to increased sympathetic traffic [26]. Plasma and urine norepinephrine levels are increased in OSA patients [27]. The hypothalamic-pituitary-adrenal [HPA] axis plays an important role in regulating alertness and sleep, and likely also in energy balance. Hypoxemia, arousals, and sleep fragmentation alter the normal function of the HPA axis [4]. Activation of the HPA axis is caused by the presence of stressors and leads to an increase in the concentrations of adrenal stress hormones, such as corticotropin-releasing hormone and vasopressin $[13,28]$. Vasopressin plays a key role in cardiovascular homeostasis. It is produced in the hypothalamus and its release leads to altered plasma osmolality, stress, and hypotension [10]. However, it is unstable in plasma and has a short half-life [10-13]. Copeptin released with vasopressin can be used instead of vasopressin as a biomarker [10-12]. Copeptin is a biomarker related to the stress response [14]. Copeptin levels have been associated with sepsis, congestive heart failure, acute $\mathrm{MI}$, and lower respiratory tract infections $[11,29,30]$. Recently, a few studies of the relationship between copeptin and OSA have been published [2,31-33]. Cinarka, et al. [2] showed that copeptin levels in patients with OSA were significantly higher than in the control group [2]. Moreover, they were also significantly higher in the severe OSA group ( $\mathrm{AHI} \geq 30$ ) compared to those with an $\mathrm{AHI}<$ 30 in the present study. Akkoyun, et al. [31] found increased serum copeptin levels in OSA patients [31]. A further two studies noted that copeptin levels were not associated with OSA [32,33]. In the present study, we found that serum copeptin levels increased in OSA.

This study had certain limitations because it included a study population of limited size. Additionally, in this study was compared OSA patients and healthy individuals. Healthy individuals did not have any comorbidities. OSA group have comorbidities such as cardiovascular diseases that may affect copeptin levels. Therefore, OSA patients were divided into two groups as mild-moderate and severe. Cardiovascular diseases such as hypertension and coronary artery disease were compared between the groups. There were no significant differences between the groups.

As conclusion, copeptin has been increasingly linked with a number of illnesses. Although the use of copeptin as a biomarker for cardiac events is well established, the use of copeptin levels as a biomarker in OSA patients is controversial. In the present study, serum copeptin levels were associated with OSA. Copeptin may be associated with particularly severe OSA. Copeptin levels may also be useful for monitoring and determining high-risk patients OSA patients. Multicentric studies are needed in future.

\section{Acknowledgement}

This research received no specific grant from any funding agency in the public, commercial or not-forprofit sectors and there is no conflict of interest.

\section{References}

1. Canto Gde L, Pachêco-Pereira C, Aydinoz S, Major PW, Flores-Mir C, et al. (2015) Biomarkers associated with obstructive sleep apnea: A scoping review. Sleep Med Rev 23: 28-45.

2. Çınarka $H$, Kayhan $S$, Karataş $M$, Asiye Yavuz, Aziz Gümüş, et al. (2015) Copeptin: A new predictor for severe obstructive sleep apnea. Ther Clin Risk Manag 11: 589594.

3. Rosen IM, Kirsch DB, Chervin RD (2017) American Academy of Sleep Medicine Board of Directors. Clinical Use of a Home Sleep Apnea Test: An American Academy of Sleep Medicine Position Statement. J Clin Sleep Med 13: 1205-1207.

4. Calvin $A D$, Albuquerque FN, Lopez-Jimenez $F$, Virend $K$ Somers (2009) Obstructive sleep apnea, inflammation, and the metabolic syndrome. Metab Syndr Relat Disord 7: 271278.

5. De Luca Canto G, Pachêco-Pereira C, Aydinoz S, Major PW, Flores-Mir C, et al. (2015) Diagnostic capability of biological markers in assessment of obstructive sleep apnea: A systematic review and meta-analysis. J Clin Sleep Med 11: 27-36.

6. Dyugovskaya L, Lavie $P$, Lavie L (2002) Increased adhesion molecules expression and production of reactive oxygen species in leukocytes of sleep apnea patients. Am J Respir Crit Care Med 165: 934-939.

7. Ciftci TU, Kokturk O, Bukan N, Bilgihan A (2004) The relationship between serum cytokine levels with obesity and obstructive sleep apnea syndrome. Cytokine 28: 87-91.

8. Badimon L, Romero JC, Cubedo J (2012) Circulating biomarkers. Thromb Res 130: 12-15.

9. Stoiser B, Mörtl D, Hülsmann M, Berger R, Struck J, et al. (2006) Copeptin, a fragment of the vasopressin precursor, as a novel predictor of outcome in heart failure. Eur $\mathrm{J}$ Clin Invest 36: 771-778.

10. Hellenkamp K, Schwung J, Rossmann H, Kaeberich A, Wachter R, et al. (2015) Risk stratification of normotensive pulmonary embolism: Prognostic impact of copeptin. Eur Respir J 46: 1701-1710

11. Khan SQ, Dhillon OS, O'Brien RJ, Struck J, Quinn PA, et al. (2007) C-terminal provasopressin (copeptin) as a novel and prognostic marker in acute myocardial infarction: Leicester Acute Myocardial Infarction Peptide (LAMP) study. Circulation 115: 2103-2110.

12. Reichlin T, Hochholzer W, Stelzig C, Laule K, Freidank H, 
et al. (2009) Incremental value of copeptin for rapid rule out of acute myocardial infarction. J Am Coll Cardiol 54: 60-68.

13. Katan M, Christ-Crain M (2010) The stress hormone copeptin: A new prognostic biomarker in acute illness. Swiss Med Wkly 140: 13101

14. Folli C, Consonni D, Spessot M, Salvini L, Velati M, et al. (2013) Diagnostic role of copeptin in patients presenting with chest pain in the emergency room. Eur $\mathrm{J}$ Intern Med 24: 189-193.

15. Gegenhuber A, Struck J, Dieplinger B, Poelz W, Pacher R, et al. (2007) Comparative evaluation of B-type natriuretic peptide, mid-regional pro-A-type natriuretic peptide, midregional pro-adrenomedullin, and Copeptin to predict 1 -year mortality in patients with acute destabilized heart failure. J Card Fail 13: 42-49.

16. Abdel-Fadeil MR, Abedelhaffez AS, Makhlouf HA, Al Qirshi GA (2017) Obstructive sleep apnea: Influence of hypertension on adiponectin, inflammatory markers and dyslipidemia. Pathophysiology 24: 305-315.

17. Berry RB, Brooks R, Gamaldo C, Susan M Harding, Robin M Lloyd, et al. (2017)AASM Scoring Manual Updates for 2017 (Version 2.4). J Clin Sleep Med 13: 665-666.

18. Narkiewicz K, van de Borne PJ, Cooley RL, Dyken ME, Somers VK (1998) Sympathetic activity in obese subjects with and without obstructive sleep apnea. Circulation 98: 772-776.

19. Grassi G, Facchini A, Trevano FQ, Dell'Oro R, Arenare $F$, et al. (2005) Obstructive sleep apnea-dependent andindependent adrenergic activation in obesity. Hypertension 46: 321-325.

20. Aihara K, Oga T, Chihara Y, Harada Y, Tanizawa K, et al. (2013) Analysis of systemic and airway inflammation in obstructive sleep apnea. Sleep Breath 17: 597-604.

21. Testelmans D, Tamisier R, Barone-Rochette G, Baguet JP, Roux-Lombard P, et al. (2013) Profile of circulating cytokines: Impact of OSA, obesity and acute cardiovascular events. Cytokine 62: 210-216.

22. Al Mutairi S, Mojiminiyi OA, Al Alawi A, Alia Al Alawi, Tahani Al Rammah, et al. (2014) Study of leptin and adiponectin as disease markers in subjects with obstructive sleep apnea. Dis Markers 2014: 706314.

23. Gustafson B (2010) Adipose tissue, inflammation and atherosclerosis. J Atheroscler Thromb 17: 332-341.

24. Archontogeorgis K, Nena E, Papanas N, Steiropoulos P (2014) Biomarkers to improve diagnosis and monitoring of obstructive sleep apnea syndrome: current status and future perspectives. Pulm Med 2014: 930535.

25. Appleton SL, Gill TK, Lang CJ, Taylor AW, McEvoy RD, et al. (2018) Prevalence and comorbidity of sleep conditions in Australian adults: 2016 Sleep Health Foundation national survey. Sleep Health 4: 13-19.

26. Carlson JT, Hedner J, Elam M, Ejnell H, Sellgren J, et al. (1993) Augmented resting sympathetic activity in awake patients with obstructive sleep apnea. Chest 103: 17631768.

27. Fletcher EC, Miller J, Schaaf JW, Fletcher JG (1987) Urinary catecholamines before and after tracheostomy in patients with obstructive sleep apnea and hypertension. Sleep 10: 35-44.

28. Spanakis EK, Wand GS, Ji N, Golden SH (2016) Association of HPA axis hormones with copeptin after psychological stress differs by sex. Psychoneuroendocrinology 63: 254261.

29. Voors AA, von Haehling S, Anker SD, Hillege HL, Struck $\mathrm{J}$, et al. (2009) OPTIMAAL Investigators. C-terminal provasopressin (copeptin) is a strong prognostic marker in patients with heart failure after an acute myocardial infarction: Results from the OPTIMAAL study. Eur Heart $\mathrm{J}$ 30: 1187-1194.

30. Müller B, Morgenthaler N, Stolz D, Schuetz $P$, Müller $C$, et al. (2007) Circulating levels of copeptin, a novel biomarker, in lower respiratory tract infections. Eur J Clin Invest 37: 145-152.

31. Akkoyun DC, Akyuz A, Tulubas F, Altıntas N, Alpsoy $S$, et al. (2015) The serum copeptin levels in obstructive sleep apnea patients with prehypertensive. Eur Rev Med Pharmacol Sci 19: 1721-1728.

32. Selcuk OT, Eyigor M, Renda L, Osma U, Eyigor H, et al. (2015) Can we use serum copeptin levels as a biomarker in obstructive sleep apnea syndrome? J Craniomaxillofac Surg 43: 879-882.

33. Ozben S, Guvenc TS, Huseyinoglu N, Sanivar HS, Hanikoglu F, et al. (2013) Low serum copeptin levels in patients with obstructive sleep apnea. Sleep Breath 17: 1187-1192. 